\title{
Adaptive e-Learning and the Learning Grid
}

\author{
Cord Hockemeyer and Dietrich Albert \\ Department of Psychology, University of Graz, Austria \\ \{Cord.Hockemeyer|Dietrich.Albert\}@uni-graz.
}

\begin{abstract}
One important aim of LeGE-WG is the integration of new eLearning methodologies into Learning Grid technology. A central issue in these new eLearning methodologies is the concept of individualised and personalised learning to be realised by adaptive tutoring systems. The adaptivity of such systems goes far beyond adapting to the users' preferences with respect to the user interface; in cooperation between computer science, psychology, and pedagogy, systems adapting, e.g., to the individual learners' current knowledge, cultural background, learning style, or special needs are developed.

Adaptive tutoring systems can be integrated into a Learning Grid at different levels of ambitiousness. We will discuss these different levels of integration based on our prior experiences with respect to reusability of adaptive learning resources.
\end{abstract}

Keywords: adaptive eLearning, Learning Grid, knowledge structures, competencies.

\section{INTRODUCTION}

Adaptive and personalised hypermedia systems have been of increasing interest in recent research and development in eLearning [1,2]. Integrating adaptive techniques enriches eLearning systems by adding psychological and pedagogical findings about knowledge and learning to technical systems.

Connecting adaptive techniques - and the underlying models of learning and knowledge - with Grid technology brings up new challenges, e.g. in the area of interoperability, but also new options.

In the following, we will first discuss adaptivity within eLearning in general as well as the knowledge space based approach pursued in our research group. Subsequently, we will discuss the issue of interoperability of adaptive eLearning systems based on our previous experiences. Finally, we look at different levels of integrating adaptive eLearning into a Learning Grid.

\section{ADAPTIVE AND PERSONALISED ELEARNING}

Using the computer for education allows - comparable to private teachers in former times - a personalised, adaptive learning, i.e. the teaching system adapts the selection and the presentation of contents to the individual learner and their learning status, their needs and preferences (see, e.g., [3]).

Within the EASEL project, many different types of adaptivity have been identified focusing on objects and objectives of adaptivity [4]. Objects of adaptivity can be, e.g., the selection of learning objects, their presentation, or the choice of input methods and devices. Objectives of adaptivity can be, e.g., the learners' pre-knowledge, their curriculum and aimed knowledge state, special needs, learning styles, or cognitive styles.

Our research group focuses on adaptivity to learners' current knowledge based on the theory of knowledge spaces [5,6]. Knowledge space theory is a psychological model for structuring domains of knowledge based on prerequisite relationships between content objects. From these structures, learning paths are derived.

The relational formalisation of this model allows an easy transfer to computer systems, especially to relational databases. Thus, it can easily be applied to adaptive eLearning [7]. 
Currently, there are two adaptive eLearning systems on the Web which are based on this theory, RATH [8] and ALEKS (see [6]).

More recent extensions of knowledge space theory distinguish between concrete learning objects or observable performances on the one side and underlying skills or competencies on the other side (see, e.g., [9-11]). These extensions also use mathematical formalisations, thus they can be applied for adaptive eLearning easily [12]. Such an application is discussed in the context of interoperability in the next section.

\section{INTEROPERABILITY AND ADAPTIVE ELEARNING}

Reusability and interoperability of computer based learning resources have received an increasing interest in recent years. This can, for instance, be seen in the development of standards and standardisation organisations in this area (see, e.g., $[13,14])$. However, all these specifications are oriented towards static material. One aim of the EASEL project in the FP5 IST programme was to extend existing interoperability standards to cover also adaptive features of learning resources [15].

In a first step, an extension to learning object metadata (LOM) standards was developed that allows a generic description of adaptive features of the material, i.e. this adaptivity element is not limited to specific types of adaptivity $[16,17]$. These metadata specifications are primarily used for search and retrieval but they can also be used by the eLearning system for realising the adaptivity itself [18].

The second step deals with interoperability between material and learning management system (LMS) directly. Adaptive material often needs to store and retrieve more information about the learner than static material. Based on AICC/SCORM $[19,20]$ standards on such information exchange, a set of information usually needed by adaptive resources has been defined that can be stored in and retrieved from the LMS through the SCORM API [21].

Based on these developments, the APeLS system was developed which is based on knowledge space theory extended by the competencies approach. This system is ready to be used from an LMS which then also does user identification and similar administrative tasks [18].

\section{ADAPTIVITY AND GRID TECHNOLOGY}

The developments described in the previous sections provide already a large step for the integration of adaptive material and adaptive services into a Learning Grid. However, the integration can be performed at different levels.

At a minimal level, the Grid provides only user authentification while all other functionality is kept within an independent adaptive server.

In a second step toward higher integration, also other information about the learner are stored within the Grid and are thus exchanged between different adaptive servers belonging to the same Grid.

While in the aforementioned levels adaptivity is basically still provided through a self-contained adaptive server, the third level of integration starts realising adaptivity in a distributed service through content repositories distributed over the Grid while the core adaptive system is still located at one server.

Finally, adaptivity itself could be realised in a distributed way through co-operation of different adaptive servers and services over the Grid. Methods for such distributed adaptive services have yet to be developed. However, integrating adaptivity into Learning Grid technology at such a high level promises to bring forward also a higher level of adaptivity than it could be realised on stand-alone services. 


\section{REFERENCES}

[1] de Bra, P., Brusilovsky, P., and Conejo, R. (2002) Eds Adaptive Hypermedia and Adaptive Web-Based Systems. Proceedings of the Second International Conference, AH 2002 Malaga, Spain, May 29 - 31, 2002. Lecture Notes in computer Science, Vol. 2347, Springer Verlag, New York.

[2] ED-MEDIA--World Conference on Educational Multimedia, Hypermedia \& Telecommunications Proceedings CD-ROM, AACE, 2002.

[3] Albert, D., \& Mori, T., (2001) Contributions of cognitive psychology to the future of e-learning. Bulletin of the Graduate School of Education, Hiroshima University, part I (Learning and Curriculum Development), Vol. 50, pp. 25-34.

[4] EASEL Requirement specification, 2001. http:// www.fdgroup.co.uk/easel/documents/D3Update.doc

[5] Doignon, J-P., and Falmagne, J-C. (1985) Spaces for the assessment of knowledge. International Journal of Man-Machine Studies, 23,175-196.

[6] Doignon, J-P., and Falmagne, J-C. (1999) Knowledge Spaces. Springer-Verlag, Berlin.

[7] Albert., D and Hockemeyer, C., (19970 Adaptive and dynamic hypertext tutoring systems based on knowledge space theory, in Benedict du Boulay and Riichiro Mizoguchi, Eds., Artificial Intelligence in Education: Knowledge and Media in Learning Systems, volume 39 of Frontiers in Artificial Intelligence and Applications, pp. 553-555, Amsterdam.

[8] Hockemeyer, C., Held, T., and Albert, D. (June 19980 RATH --- a relational adaptive tutoring hypertext WWW--environment based on knowledge space theory, in Christer Alvegård, Eds, CALISCE 98: Proceedings of the Fourth International Conference on Computer Aided Learning in Science and Engineering, pp. 417-423, Göteborg, Sweden. Chalmers University of Technology.

[9] Albert., D and Lukas, J., (1999) Eds. Knowledge Spaces: Theories, Empirical Research, Applications. Lawrence Erlbaum Associates, Mahwah, NJ

[10] Düntsch, I., and Gediga, G. (1995) Skills and knowledge structures. British Journal of Mathematical and Statistical Psychology, 48,9-27.

[11] Korossy, K., (1997) Extending the theory of knowledge spaces: A competence-performance approach. Zeitschrift für Psychologie, 205,53-82.

[12] Hockemeyer, C., (2002) Extending the Competence-Performance-Approach for Building Dynamic and Adaptive Tutoring Systems, presentation at the $33^{\text {rd }}$ European Mathematical Psychology Group (EMPG) Meeting, Bremen, Germany.

[13] IEEE Learning Technology Standards Committee (LTSC), http://ltsc.ieee.org/ .

[14] IMS Global Learning Consortium Inc., http://www.imsproject.org/ .

[15] EASEL (Educator Access to Services in the Electronic Landscape), EC Grant IST-199910051. URL: http://www.fdgroup.co.uk/easel/ .

[16] Conlan, O., Hockemeyer, C., Lefrere, P., Wade, V., and Albert, D., (2001) Extending educational metadata schemas to describe adaptive learning resources, in Hugh Davies, Yellowlees Douglas, and David G. Durand, editors. Hypertext '01: Proceedings of the twelfth ACM Conference on Hypertext and Hypermedia, New York. 1, pp. 161-162. Association for Computing Machinery, ACM.

[17] Albert, D., Hockemeyer, C., Conlan, O., and Wade. V., (2001) Reusing adaptive learning resources. in C.-H. Lee et al., editor, Proceedings of the International Conference on Computers in Education ICCE/SchoolNet2001, volume 1, pp. 205-210, 2001.

[18] Conlan, O., Hockemeyer, C., Wade, V., and Albert. D. Metadata driven approaches to facilitate adaptivity in personalized eLearning systems. International Journal on Information Systems in Education, to appear.

[19] Aviation Industry CBT Committee (AICC), http://www.aicc.org/ .

[20] SCORM, Sharable Content Object Reference Model, (January 2001) Version 1.1, Advanced Distributed Learning (http://www.adlnet.org).

[21] Conlan, O., Hockemeyer, C., Wade, V., and Albert, D (2002) An architecture for integrating adaptive hypermedia service with open learning environments, in Proceedings of ED-MEDIA, World Conference on Educational Multimedia, Hypermedia, \& Telecommunications. 